\title{
Remediation for Human Research Subjects Protections Non-Compliance: Concepts and Approaches
}

\section{Jay Johnson}

Division of Pastoral Care, CHI St. Luke's Health/Baylor St. Luke's Medical Ctr, 6720 Bertner Ave., Houston, TX 77030

"Corresponding author: Jay Johnson, TMC, Catholic Chaplain's Corps, Division of Pastoral Care, CHI St. Luke's Health/Baylor St. Luke's Medical Ctr, 6720 Bertner Ave., Houston, TX 77030, USA, Tel: 832-372-3511; E-mail: ralph.j.johnson.mil@mail.mil (or) jay.johnson@us.army.mil

Received date: March 09, 2015; Accepted date: April 22, 2015; Published date: April 26, 2015

Copyright: () 2015 Johnson J. This is an open-access article distributed under the terms of the Creative Commons Attribution License, which permits unrestricted use, distribution, and reproduction in any medium, provided the original author and source are credited.

\begin{abstract}
Approximating the extent of non-compliance regarding human research subjects protections is controversial. Nevertheless, based on recent research it can be conservatively estimated at about 1,163 cases per year in the United States alone; whereas, less conservative surveys estimate the problem is more widespread (approx.. 84\% higher). Additionally, many notorious cases were preceded by earlier offenses, so there is recidivism. The conventional response to the problem is punitive, that is suspension and/or termination. This usually entails losing the research, research personnel, funding, and bad publicity and loss of the public's confidence. Unlike punitive action, proponents for an alternative response, namely remediation, argue it offers prevention of recidivism, restoration of trust, and risk management because action plans are established. Yet, there are few if any reports on systems, models, or methodical approaches regarding practical aspects of remediation for human research subjects protection non-compliance. This article is a first yet critical step to fill that void of information in that it: provides a conceptual report on a general linear progression of steps to follow, a triage model or pathway to remediation, conducting a general assessment and specific inventory, visual displaying, causal identification, courses of action, prevention/education, and near zero defect accomplishment. The hope is that researchers can use the fundamental tool chest of ideas and methods described herein-if necessary, and hopefully that will never be the case-to tailor remediation efforts to their particular circumstances.
\end{abstract}

Keywords: Human research subjects protections; Research problems; Non-compliance; Remediation, Regulatory oversight

\section{Introduction}

According to DuBois et al. [1], the frequency of researcher wrongdoing is fairly common with almost all research intensive institutions in the United States reporting some variant of it over a two year period. A large portion of this wrongdoing $(>50 \%)$ can be attributed conservatively to human research subjects protections noncompliance. Their definition of researcher wrongdoing falls under the general rubric of "Failure to Follow Procedures," and currently most research institutions' require their researchers include their procedures and following those procedures in their Institutional Review Board (IRBs) submission approval [2-4]. Thus, and less conservatively, almost $100 \%$ of researcher wrong doing can be attributed ultimately to human research subjects protections noncompliance. Using their extrapolation formula, a conservative estimate of human research subject protection non-compliance is about 1,163 cases per year in the United States alone; whereas, less conservative surveys estimate the problem at approx. $84 \%$ higher or 2,140 cases per year. Most of the offenders in high-profile cases were repeat offenders in that they had offended before being caught $[5,6]$. The problem with estimating the true extent of non-compliance is that it-by definition-it is deviant behavior and therefore is hidden and can never be fully known $[7,8]$.

Whatever the numbers, it is the nightmare of IRBs, scientific communities, and researchers. Auditors have come and gone, and after examination and analyses, their results demonstrate substantial deficiencies, deviations, violations, and abuses in the protection processes and regulatory practices that affect human research subjects. After such results, conventionally, the IRB assigns a level of noncompliance based on the auditors' reports and other mitigating factors and renders its decision: suspension or termination [9-12]. Despite this textbook approach, there is an alternative third optionremediation $[13,14]$. Indeed, advocates for remediation, argue it offers prevention of recidivism, restoration of trust, and risk management because action plans are established.

The fact that research institutions/agencies and their IRB's policies and procedures have established provisions for remediation at all is a testament and admission that otherwise valuable research studies can and do go awry in terms of observing protections for human research subjects [15]. Indeed, both IRBs and investigators may encounter the unpleasant need to develop adequate remediation and prevent future violations. A cursory world-wide internet search for the inclusion of remediation in policy and procedures yielded results suggesting that there were about as many mentions of remediation in institutions' standard human subjects protection procedures as there were research dedicated institutions. But most of them merely mentioned it. Regardless of the acknowledgment that the "baby should not be thrown out with the bath water," little, if any, in-depth information exists in the literature regarding how to actually remediate (i.e., fix up, clean up and prevent) deviations and violations of regulatory protections for human research subjects. This is likely because such remediation programs are almost never publicized given their sensitive and embarrassing nature. If they are reported at all, it is only as vague glossed-over, finished products and to the limited extent required by their IRBs for public allocution. Thus, particular aspects of the remediation are known only to those who are privy to them. Therefore, remediation is a dark, murky, and nebulous region, not 
often discussed in open source forums. Nevertheless, given the fact that it is seemingly almost universally acknowledged as necessary, it is in serious need of consideration and explication to ensure the integrity of the scientific process regarding the rights and protections for human research subjects.

Therefore, this article provides a conceptual and methodological tool chest to use in addressing non-compliance with protections for human research subjects as a first, but critical step to fill the information gap. The concepts and approaches are drawn from the author's firsthand experience repairing, restoring, and resurrecting suspended research programs and a sparse open-sourced literature. It is hoped that the ideas and methods offered in this report will not be needed, as researchers everywhere and at all times should be circumspect in their observance of protections and best practices with respect to human research subjects. One way to avoid emotionally draining and financially expensive remediation is to ensure compliance with the protections established for human research subjects in the first place.

However, even after the best of planning, mistakes can be made. If remediation is warranted, IRBs and investigators and nurse research study coordinators and other research study personnel alike can draw on the step-by-step ideas and methods offered herein and translate them into systematic formulations for remediation efforts relevant to their particular circumstances. Note that although the presentation here is a step-by-step progression in the interest of clarity and order (Figure 1), the progression is iterative and steps can even be skipped or revisited.

Indeed, the information in this article may prove useful for researchers who find themselves in the unenviable position of proposing a course of remediation to an IRB and discussing it knowledgeably with IRB members.

Here, "problems with human research subjects" subsumes (1) noncompliance, deviations, and violations of regulations or related intraorganizational policies and procedures and (2) protocol deviations/ violations as they relate to protections for human research subjects. This report is limited in scope to problems associated with human research subjects as opposed to issues surrounding data safety and monitoring (e.g., adverse events), even though they might overlap and be related. Also, remediation here refers to the provision of a remedy at the systems level [16]. This article assumes the legal/ethical definition of remediation, which incorporates an environmental approach, specifically, 'remedying something, esp. the reversal or stopping of damage; affording a remedy and obtaining redress and remedy wrongs and abuses and abate faults or supply defects' [17]. Essentially, it encompasses the cleaning up and fixing up, redemption, restoration or removal, and enhanced protection of human research subjects with an eye toward prevention of abuses [18]. Thus, in terms of protections for human research subjects, remediation covers the amelioration of existing problems and the risk reduction of future problems.

\section{Extent and Severity-General Assessment}

Auditors' reports should not be relied on exclusively. Usually they represent only a sampling that detected significant non-compliance, which merely scratches the surface and does not delve into the full extent of problems. Once problems are detected in significant amounts, any consideration of remediation should be predicated based on a comprehensive general assessment survey, the results of which must be reported to the IRB [19]. The IRB likely will launch its own investigation or request investigators to launch one with the IRB's significant oversight. If the IRB does not, then the investigators should initiate their own investigation in the interest of demonstrating good faith. (Indeed, one reason significant problems exist is that no fairly regular internal audit is in place or, if it is in place, the audit is not comprehensive enough).

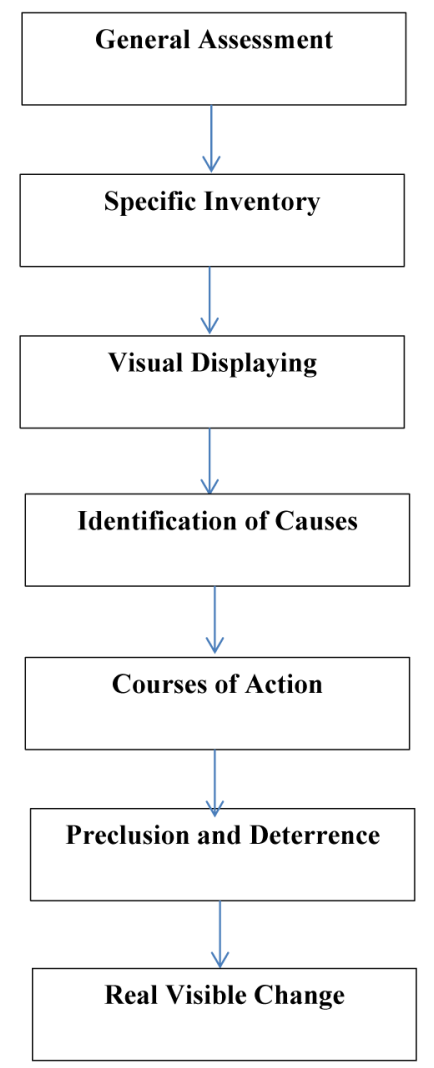

Figure 1: Remediation Steps.

A needs assessment survey entails a complete inventory and description of particular types and amounts of non-compliance. This is the "what happened(s)" related to a regulatory standard that was not observed. The types of problems can be identified and ranked in terms of severity. The particular IRB assigns the severity classification, not investigators. Also, severity can be further complicated or exacerbated by whether it is unintentional or willful. This needs assessment can then help in a triage for both investigators and the IRB regarding (1) how big, (2) how bad, (3) how fixable is/are the problem(s), and (4) whether the study or program is worth salvaging (Figure 2). Note, Figure 2 depicts just such a classic triage or tree logic model in terms of decisions or outcomes resulting from an audit of human research subjects protections. It is based on an iterative review of what little exists in terms of intensive research institutions' procedures and the author's practical experiences. It is drawn as a latticework of statement or question nodes connected by "yes" and "no" answers and outcomes. The trigger is the top box, the diamonds that follow are the yes and no questions/answers, which lead to boxes that are outcomes. The eventual outcome following the latticework to its logical conclusion is Remediation. 
Addressing each issue involves collaboration between the IRB and investigators, but nothing can be considered or done without first obtaining IRB approval [20]. A general assessment will give everyone a pretty good idea of whether remediation is possible or the research should be terminated. Predicated on the consideration and incorporation of similarities in multiple existing processes, these types of triage models are well-formed in that they capture the intent and logic of those processes and are tuned. And they only improve with more research and information.

Few other, if any, graphic depictions exist in the open-sourced literature with the possible exception of one model proposed previously by the Veterans Administration (VA) [21]. The model was included in a public allocution report that was a part of remediation for egregious and continuous human subjects protections noncompliance and violations particularly in terms of the VA's research collaborations with the University of California-San Francisco. Though exceptionally elaborate and detailed, the chief disadvantage of the VA model is that their model is specific only to the VA system and it is rather complicated. Nevertheless, it footnotes remediation as an eventual possibility after many and varied considerations. However, there is some added confusion in that any remediation must both be in a specified time period and acceptable and without justification by VA policy. Unlike the VA model, the models proposed in Figures 1 and 2 are probably better in the sense they are more generic and direct and accomplish the same purpose.

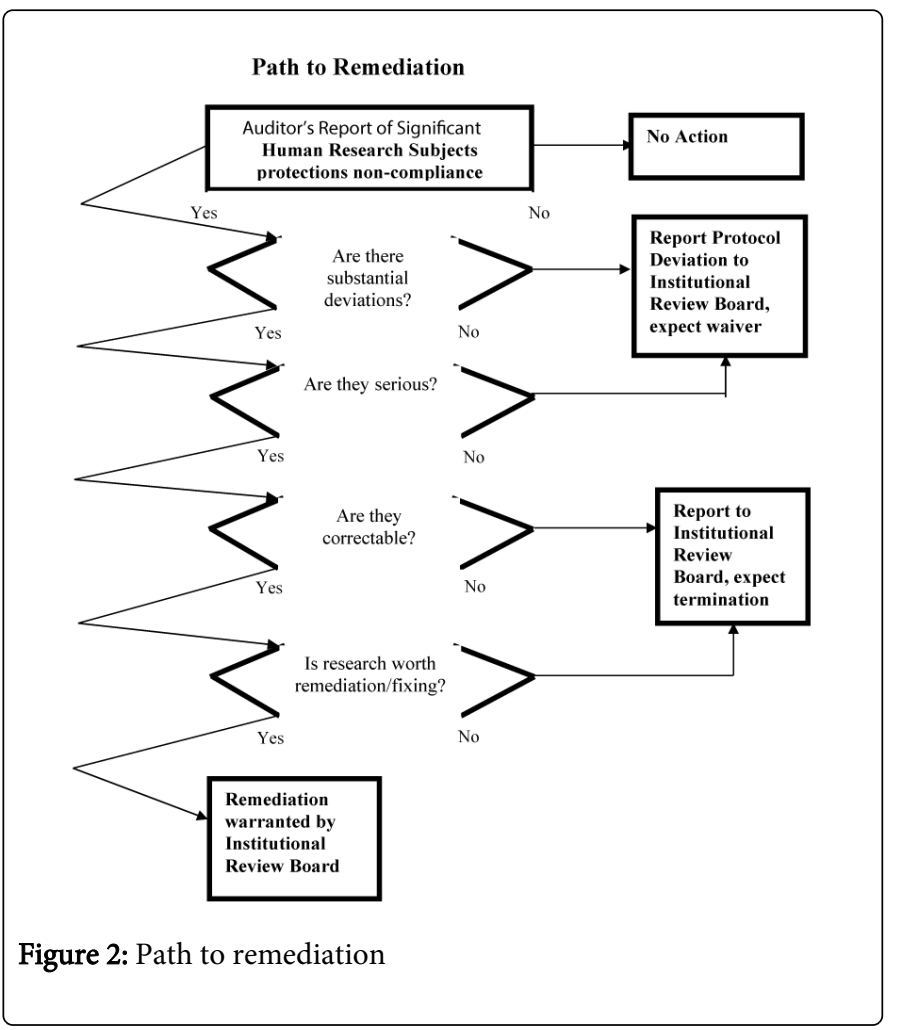

\section{Entities, Boundaries, Containment/Suspension, or Termination-Specific Inventory}

In any human subject's cleanup effort, there is an entity on which work is to be done, which can be a single study, research program, or organization (e.g., division, department, company, institution, agency). Similar studies are more commonly conducted at the same time in programs or organizations with common scientific interests by the same research workers using common systems and practices under the same leadership. Thus, non-compliance with protections for human research subjects in one place may also occur in other nearby places. For example, extremely serious violations of protections for human research subjects found in one study at the California Department of Veterans Affairs (VA) (i.e., an entity) led to discovery of similar violations across the VA and some affiliated universities, eventually resulting in a suspension of all research in the entire VA system until matters could be studied and remediated [22-24]. Thus, boundaries must be approximated and then a determination made concerning the extent to which non-compliance has breached those boundaries. "Containment" (i.e., "damage control") then is the next consideration. That is, should the research in general or particular studies be allowed to continue or be suspended to check continuation, migration, or even proliferation of non-compliance (e.g., the California VA)? Containment in terms of remediating noncompliance with protections for human research subjects generally means the IRB's temporary suspension until an assessment and inventory of all the problems and their severity among all the studies in an entity is conducted. This leads to either (1) answers to subsequent questions related to comprehensive planning and marshalling of resources to address past problems and current practices or (2) termination.

\section{Breadth and Depth: Creep, Seepage, Spillage/Spillover- Visual Displaying}

A further consideration is appraising the breadth and depth of problems with human research subjects or assessing how many and how deep and pervasive the problems identified are. This may be articulated as an epidemiology of the amounts, occurrences, and locations of types of problems with protections for human research subjects. This appraisal also will serve as a baseline for evaluating the remediation effectiveness, or "measuring legacy" or "residual from the cleanup." The amount and strength of the residual will determine lingering implications and repercussions for what cannot be fixed up and whether after remediation circumstances can be considered salvaged. A residual may exist even if things are fixed up.

\section{Visual displaying}

Visual displays can more accurately point to remediation priorities, actions, and solutions in terms of rank ordering and scheduling remediation, especially on a large scale [25-27]. Such displays spatially and comprehensively depict the locations, distributions, and risks of occurrence and recurrence, extent, abundance, depth, density, temporality, and even connectivity of seemingly unrelated or different types of problems from the preceding general assessment and specific inventory. Visual displays may reveal defective systemic processes and possible changes through time in research organizations and their practices, where multiple studies may be conducted, some at the same time and others at different times, by the same personnel under the same leadership with similar errant procedures.

Firms that conduct remediation on large-scale eco-disasters and hazardous waste cleanups use very sophisticated, high-tech visual graphics. ${ }^{1}$ However, a visual display can be effectively yet simply accomplished by arraying types of problems in columns with their occurrence over time in the rows of spreadsheets, with each spreadsheet representing one study. The way in which they are arrayed should be consistent across spreadsheets. Generally, the way to array 
Citation: Johnson J (2015) Remediation for Human Research Subjects Protections Non-Compliance: Concepts and Approaches. J Clinic Res

Page 4 of 10

non-compliance with human research subjects protections that provides the most information is by rank ordering left to right from most severe to least severe non-compliance problems. The first three columns should be the study participant identification numbers, a date (preferably enrollment date), and research study coordinator(s) responsible, respectively. Cells can be color-coded in terms of severity (e.g., red most severe, yellow moderately severe, green no problem (Figures 3-6). For example, Figure 3 depicts the ideal standard, specifically, a well-run study under the same research program lab where all facets of human subjects protections being measured are met or exceeded.

\begin{tabular}{|c|c|c|c|c|c|c|c|c|c|}
\hline WLID & Date & SRC & $\begin{array}{l}\text { Missing } \\
\text { ICF }\end{array}$ & $\begin{array}{l}\text { ICF in } \\
\text { Wrong } \\
\text { Language }\end{array}$ & $\begin{array}{l}\text { Wrong } \\
\text { ICF }\end{array}$ & $\begin{array}{l}\text { Improperly } \\
\text { Completed } \\
\text { ICF }\end{array}$ & $\begin{array}{l}\text { Missing } \\
\text { HIPAA } \\
\text { Info }\end{array}$ & $\begin{array}{l}\text { Missing RSC } \\
\text { Info/Signature }\end{array}$ & $\begin{array}{l}\text { Consenting } \\
\text { P\&P Not } \\
\text { Followed }\end{array}$ \\
\hline WLS40029 & $3 / 9 / 3009$ & Ms. Pristine & No & No & No & No & No & No & No \\
\hline WLS40028 & $3 / 6 / 2009$ & Ms. Pristine & No & No & No & No & No & No & No \\
\hline WLS40027 & $3 / 5 / 2009$ & Ms. Pristine & No & No & No & No & No & No & No \\
\hline WLS40026 & $3 / 5 / 2009$ & Ms. Pristine & No & No & No & No & No & No & No \\
\hline WLS40025 & $3 / 4 / 2009$ & Ms. Pristine & No & No & No & No & No & No & No \\
\hline WLS40024 & $3 / 3 / 2009$ & Ms. Pristine & No & No & No & No & No & No & No \\
\hline WLS40023 & $3 / 2 / 2009$ & Ms. Pristine & No & No & No & No & No & No & No \\
\hline WLS40022 & $2 / 27 / 2009$ & Ms. Pristine & No & No & No & No & No & No & No \\
\hline WLS40021 & $2 / 26 / 2009$ & Ms. Pristine & No & No & No & No & No & No & No \\
\hline WLS40020 & $2 / 25 / 2009$ & Ms. Pristine & No & No & No & No & No & No & No \\
\hline WLS40019 & $2 / 25 / 2009$ & Ms. Pristine & No & No & No & No & No & No & No \\
\hline WLS40018 & $2 / 24 / 2009$ & Ms. Pristine & No & No & No & No & No & No & No \\
\hline WLS40017 & $2 / 23 / 2009$ & Ms. Pristine & No & No & No & No & No & No & No \\
\hline WLS40016 & $2 / 23 / 2009$ & Ms. Pristine & No & No & No & No & No & No & No \\
\hline WLS40015 & $2 / 20 / 2009$ & Ms. Pristine & No & No & No & No & No & No & No \\
\hline WLS40014 & $2 / 19 / 2009$ & Ms. Pristine & No & No & No & No & No & No & No \\
\hline WLS40013 & $2 / 18 / 2009$ & Ms. Stellar & No & No & No & No & No & No & No \\
\hline WLS40012 & $2 / 17 / 2009$ & Ms. Stellar & No & No & No & No & No & No & No \\
\hline WLS40011 & $2 / 17 / 2009$ & Ms. Stellar & No & No & No & No & No & No & No \\
\hline WLS40010 & $2 / 13 / 2009$ & Ms. Stellar & No & No & No & No & No & No & No \\
\hline WLS40009 & $2 / 11 / 2009$ & Ms. Stellar & No & No & No & No & No & No & No \\
\hline WLS40008 & $2 / 10 / 2009$ & Ms. Stellar & No & No & No & No & No & No & No \\
\hline WLS40007 & $2 / 9 / 2009$ & Ms. Stellar & No & No & No & No & No & No & No \\
\hline WLS40006 & $2 / 9 / 2009$ & Ms. Stellar & No & No & No & No & No & No & No \\
\hline WLS40005 & $2 / 6 / 2009$ & Ms. Stellar & No & No & No & No & No & No & No \\
\hline WLS40004 & $2 / 5 / 2009$ & Ms. Stellar & No & No & No & No & No & No & No \\
\hline WLS40003 & $2 / 5 / 2009$ & Ms. Stellar & No & No & No & No & No & No & No \\
\hline WLS40002 & $2 / 3 / 2009$ & Ms. Stellar & No & No & No & No & No & No & No \\
\hline WLS40001 & $2 / 2 / 2009$ & Ms. Stellar & No & No & No & No & No & No & No \\
\hline
\end{tabular}

Figure 3: Compliance to standard, study \#1 Tumult University, Wankowitz Labs.

Visual displays also provide clues about the dynamics of problems; for example, they can point to possible "creep," "seepage," or "spillage/ spillover" in terms of other studies or research programs.

These types of patterns are ideal types and do not exhaust the range of patterns or combinations of human research subjects protections non-compliance. Rather, they are presented in an attempt to demonstrate the utility of visual displays. Note that visual displays simultaneously account for and convey how long or deep and pervasive and how serious the non-observance of protections for human research subjects and related problems is across studies. Electronic spreadsheets permit quick sorting and merging, especially by color codes, according to various criteria for the purpose of tracking, analyzing, and reporting. (This also makes them useful for accounting and auditing subsequent corrective actions.)

1 Unlike the human research subjects regulatory literature, there are many reports in the scientific literature on remediation regarding eco-disasters, which are replete with actual, practical case studies of remediation efforts and the conceptual models that underscored them. Ironically, many of the concepts described here were borrowed from that literature - as remediation plans have in common the goal of cleaning up messes [39-43]. 
Citation: Johnson J (2015) Remediation for Human Research Subjects Protections Non-Compliance: Concepts and Approaches. J Clinic Res

Page 5 of 10

Creep: In terms of human subjects, creep is the gravitation for whatever reason (e.g., change in management, systems, equipment, degrading practices, untrained personnel, inordinate workloads) toward instances of non-compliance (Figure 4). Since the intent of the figures is to depict change over time, what the figures do not portray is that non-compliance may have been standard practice from the start of the studies. Figures 4 and 5 depict a substantial increase in workload over time for one study research coordinator (SRC), even with the addition of new coordinators; this resulted in a subsequent, though not critical, slippage in human research subjects protections for the veteran SRC.

\begin{tabular}{|c|c|c|c|c|c|c|c|c|c|}
\hline WLID & Date & SRC & $\begin{array}{l}\text { Missing } \\
\text { ICF }\end{array}$ & $\begin{array}{l}\text { ICF in Wrong } \\
\text { Language }\end{array}$ & Wrong ICF & $\begin{array}{l}\text { Improperly } \\
\text { Completed } \\
\text { ICF }\end{array}$ & $\begin{array}{l}\text { Missing } \\
\text { HIPAA } \\
\text { Info }\end{array}$ & $\begin{array}{l}\text { Missing RSC } \\
\text { Info/Signature }\end{array}$ & $\begin{array}{l}\text { Consenting } \\
\text { P\&P Not } \\
\text { Followed }\end{array}$ \\
\hline WLS10029 & $3 / 9 / 3009$ & Ms. Malevolent & Yes & N/A & N/A & N/A & Yes & N/A & Yes \\
\hline WLS10028 & $3 / 6 / 2009$ & Ms. Lazy & No & No & No & Yes & Yes & Yes & Yes \\
\hline WLS10027 & $3 / 5 / 2009$ & Ms. Pristine & No & No & No & No & Yes & No & No \\
\hline WLS10026 & $3 / 5 / 2009$ & Ms. Incompetent & No & Yes & Yes & Yes & No & No & Yes \\
\hline WLS10025 & $3 / 4 / 2009$ & Ms. Lazy & No & No & No & Yes & Yes & Yes & Yes \\
\hline WLS10024 & $3 / 3 / 2009$ & Ms. Pristine & No & No & No & Yes & No & No & No \\
\hline WLS10023 & $3 / 2 / 2009$ & Ms. Incompetent & No & Yes & Yes & Yes & No & No & Yes \\
\hline WLS10022 & $2 / 27 / 2009$ & Ms. Malevolent & Yes & N/A & N/A & N/A & Yes & N/A & Yes \\
\hline WLS10021 & $2 / 26 / 2009$ & Ms. Pristine & No & No & No & No & No & No & No \\
\hline WLS10020 & $2 / 25 / 2009$ & Ms. Incompetent & No & Yes & Yes & Yes & No & No & Yes \\
\hline WLS10019 & $2 / 25 / 2009$ & Ms. Pristine & No & No & No & No & No & No & No \\
\hline WLS10018 & $2 / 24 / 2009$ & Ms. Lazy & No & No & No & Yes & Yes & Yes & Yes \\
\hline WLS10017 & $2 / 23 / 2009$ & Ms. Pristine & No & No & No & No & No & No & No \\
\hline WLS10016 & $2 / 23 / 2009$ & Ms. Malevolent & Yes & N/A & N/A & N/A & Yes & N/A & Yes \\
\hline WLS10015 & $2 / 20 / 2009$ & Ms. Pristine & No & No & No & No & No & No & No \\
\hline WLS10014 & $2 / 19 / 2009$ & Ms. Incompetent & No & Yes & Yes & Yes & No & No & Yes \\
\hline WLS10013 & $2 / 18 / 2009$ & Ms. Pristine & No & No & No & No & No & No & No \\
\hline WLS10012 & $2 / 17 / 2009$ & Ms. Pristine & No & No & No & No & No & No & No \\
\hline WLS10011 & $2 / 17 / 2009$ & Ms. Pristine & No & No & No & No & No & No & No \\
\hline WLS10010 & $2 / 13 / 2009$ & Ms. Pristine & No & No & No & No & No & No & No \\
\hline WLS10009 & $2 / 11 / 2009$ & Ms. Pristine & No & No & No & No & No & No & No \\
\hline WLS10008 & $2 / 10 / 2009$ & Ms. Pristine & No & No & No & No & No & No & No \\
\hline WLS10007 & $2 / 9 / 2009$ & Ms. Pristine & No & No & No & No & No & No & No \\
\hline WLS10006 & $2 / 9 / 2009$ & Ms. Pristine & No & No & No & No & No & No & No \\
\hline WLS10005 & $2 / 6 / 2009$ & Ms. Pristine & No & No & No & No & No & No & No \\
\hline WLS10004 & $2 / 5 / 2009$ & Ms. Pristine & No & No & No & No & No & No & No \\
\hline WLS10003 & $2 / 5 / 2009$ & Ms. Pristine & No & No & No & No & No & No & No \\
\hline WLS10002 & $2 / 3 / 2009$ & Ms. Pristine & No & No & No & No & No & No & No \\
\hline WLS10001 & $2 / 2 / 2009$ & Ms. Pristine & No & No & No & No & No & No & No \\
\hline
\end{tabular}

Figure 4: Non-compliance creep study \#2, Tumult University, Wankowitz Labs.

Seepage/spillover: Seepage is non-compliance trickling in. For example, in Figure 5, a study research coordinator with lax practices was assigned as a substitute for a study that normally was staffed by a study coordinator with pretty stringent habits. Spillage or spillover is where errant practices and problems seem to literally and suddenly overflow into a place that was once pristine (Figure 5). For example, Figure 6 shows a study in the same lab (i.e., entity) where SRCs with errant human research subjects protection practices took over from a coordinator with very good practices with disastrous consequences.

\section{Visual displaying}

Figures 3-6 represent common types of human research subjects non-compliance but does not cover all possible types that might be found. Also, note that these figures may unfairly lay blame on personnel for problems, whereas just as easily such problems could be the result of defective infrastructure, systems, or other aspects of the research. Nevertheless, whenever problems exist with compliance with human research subjects protections, questions should be raised regarding the leadership and supervision and why there was no internal monitoring or alert mechanisms. Put differently, where was the principal investigator and what was this person doing, as this person is ultimately responsible for the non-compliance? 
Citation: Johnson J (2015) Remediation for Human Research Subjects Protections Non-Compliance: Concepts and Approaches. J Clinic Res

Page 6 of 10

Advantages of visual displaying: highlighting patterns and/or pointing to sources: Using visual displays, as opposed to simple rank ordering, helps avoid the error of merely assigning the highest priority in remediation to the aspect or area that seems the most distressed. Rather, visual displays might point to multiple areas that when addressed afford the greatest potential to reasonably improve overall circumstances within resource constraints. Also, visual displays help in avoiding lumping categories together and artificially inflating/deflating their apparent severity. Simply put, visual displays provide a graphic depiction of the spatial nature and relationship of problem(s). These distributions can be termed "clusters." Their risk of occurrence can be further measured statistically, if need be.

Processes, sources, and pathways-identification of causes: In terms of developing courses of action for the remediation of problems in protecting human research subjects, guidelines should not only identify the problems for repair but also identify the processes that led to the problems in the first place. These guidelines include asking "how it happened" and "why it happened." Once explicated, the natural logical progression is toward identification of measures for cleanup and incorporating counter-measures to reduce and prevent further events $[28,29]$. Proposed interventions must have measurable effects on both the repair and the processes that initially led to the problems. Finally, the interventions should be supported by additional extensions of plans and actions that deal with other possible sources of problems. Note that visual displays also help point out what can be referred to as "parent-centers" (i.e., ultimate progenitors) of problems.

\begin{tabular}{|c|c|c|c|c|c|c|c|c|c|}
\hline LID & Date & SRC & $\begin{array}{l}\text { Missing } \\
\text { ICF }\end{array}$ & $\begin{array}{l}\text { ICF in } \\
\text { Wrong } \\
\text { Language }\end{array}$ & $\begin{array}{l}\text { Wrong } \\
\text { ICF }\end{array}$ & $\begin{array}{l}\text { Improperly } \\
\text { Completed } \\
\text { ICF }\end{array}$ & $\begin{array}{l}\text { Missing } \\
\text { HIPAA } \\
\text { Info }\end{array}$ & $\begin{array}{l}\text { Missing RSC } \\
\text { Info/Signature }\end{array}$ & $\begin{array}{l}\text { Consenting P\&P } \\
\text { Not Followed }\end{array}$ \\
\hline WLS20028 & $3 / 6 / 2009$ & Mr. Lazy & No & No & No & Yes & Yes & Yes & Yes \\
\hline WLS20027 & $3 / 5 / 2009$ & Ms. Pristine & No & No & No & No & No & No & No \\
\hline WLS20026 & $3 / 5 / 2009$ & Ms. Pristine & No & No & No & No & No & No & No \\
\hline WLS20025 & $3 / 4 / 2009$ & Mr. Lazy & No & No & No & Yes & Yes & Yes & Yes \\
\hline WLS20024 & $3 / 3 / 2009$ & Ms. Pristine & No & No & No & No & No & No & No \\
\hline WLS20023 & $3 / 2 / 2009$ & Ms. Pristine & No & No & No & No & No & No & No \\
\hline WLS20022 & $2 / 27 / 2009$ & Mr. Lazy & No & No & No & Yes & Yes & Yes & Yes \\
\hline WLS20021 & $2 / 26 / 2009$ & Ms. Pristine & No & No & No & No & No & No & No \\
\hline WLS20020 & $2 / 25 / 2009$ & Ms. Pristine & No & No & No & No & No & No & No \\
\hline WLS20019 & $2 / 25 / 2009$ & Ms. Pristine & No & No & No & No & No & No & No \\
\hline WLS20018 & $2 / 24 / 2009$ & Ms. Pristine & No & No & No & No & No & No & No \\
\hline WLS20017 & $2 / 23 / 2009$ & Ms. Pristine & No & No & No & No & No & No & No \\
\hline WLS20016 & $2 / 23 / 2009$ & Ms. Pristine & No & No & No & No & No & No & No \\
\hline WLS20015 & $2 / 20 / 2009$ & Ms. Pristine & No & No & No & No & No & No & No \\
\hline WLS20014 & $2 / 19 / 2009$ & Ms. Pristine & No & No & No & No & No & No & No \\
\hline WLS20013 & $2 / 18 / 2009$ & Ms. Pristine & No & No & No & No & No & No & No \\
\hline WLS20012 & $2 / 17 / 2009$ & Ms. Pristine & No & No & No & No & No & No & No \\
\hline WLS20011 & $2 / 17 / 2009$ & Ms. Pristine & No & No & No & No & No & No & No \\
\hline WLS20010 & $2 / 13 / 2009$ & Ms. Pristine & No & No & No & No & No & No & No \\
\hline WLS20009 & $2 / 11 / 2009$ & Ms. Pristine & No & No & No & No & No & No & No \\
\hline WLS20008 & $2 / 10 / 2009$ & Ms. Pristine & No & No & No & No & No & No & No \\
\hline WLS20007 & $2 / 9 / 2009$ & Ms. Pristine & No & No & No & No & No & No & No \\
\hline WLS20006 & $2 / 9 / 2009$ & Ms. Pristine & No & No & No & No & No & No & No \\
\hline WLS20005 & $2 / 6 / 2009$ & Ms. Pristine & No & No & No & No & No & No & No \\
\hline WLS20004 & $2 / 5 / 2009$ & Ms. Pristine & No & No & No & No & No & No & No \\
\hline WLS20003 & $2 / 5 / 2009$ & Ms. Pristine & No & No & No & No & No & No & No \\
\hline WLS20002 & $2 / 3 / 2009$ & Ms. Pristine & No & No & No & No & No & No & No \\
\hline WLS20001 & $2 / 2 / 2009$ & Ms. Pristine & No & No & No & No & No & No & No \\
\hline
\end{tabular}

Figure 5: Non-compliance seepage study \#3, Tumult University, Wankowitz Labs.

Repair and restoration and/or removal and replacement-courses of action: Repair and restoration and/or removal and replacement are possible ideal types of courses of action for correction, cleanup, and/or abatement. These courses of action address "what will be done." They are developed in conjunction with the IRB and with an eye toward available resources. Again, visual displays help in providing solutions that result in a balance between tolerable levels of past problems and improvements given the existing resources. Two types of remediation action can be considered: (1) exposure/restoration and (2) removal/ replacement. (Cleanup services that specialize in eco-disasters and hazardous waste and materials elimination use the terms in-sitsu and ex-sitsu, respectively).* 
Citation: Johnson J (2015) Remediation for Human Research Subjects Protections Non-Compliance: Concepts and Approaches. J Clinic Res

\begin{tabular}{|c|c|c|c|c|c|c|c|c|c|}
\hline WLID & Date & SRC & $\begin{array}{l}\text { Missing } \\
\text { ICF }\end{array}$ & $\begin{array}{l}\text { ICF in Wrong } \\
\text { Language }\end{array}$ & $\begin{array}{l}\text { Wrong } \\
\text { ICF }\end{array}$ & $\begin{array}{l}\text { Improperly } \\
\text { Completed } \\
\text { ICF }\end{array}$ & $\begin{array}{l}\text { Missing } \\
\text { HIPAA } \\
\text { Info }\end{array}$ & $\begin{array}{l}\text { Missing RSC } \\
\text { Info/Signature }\end{array}$ & $\begin{array}{l}\text { Consenting P\&P } \\
\text { Not Followed }\end{array}$ \\
\hline WLS30029 & $3 / 9 / 3009$ & Ms. Malevolent & Yes & N/A & N/A & N/A & Yes & N/A & Yes \\
\hline WLS30028 & $3 / 6 / 2009$ & Ms. Malevolent & Yes & N/A & N/A & N/A & Yes & N/A & Yes \\
\hline WLS30027 & $3 / 5 / 2009$ & Mr. Lazy & No & No & No & Yes & Yes & Yes & Yes \\
\hline WLS30026 & $3 / 5 / 2009$ & Ms. Malevolent & Yes & $\mathrm{N} / \mathrm{A}$ & $\mathrm{N} / \mathrm{A}$ & N/A & Yes & N/A & Yes \\
\hline WLS30025 & $3 / 4 / 2009$ & Mr. Lazy & No & No & No & Yes & Yes & Yes & Yes \\
\hline WLS30024 & $3 / 3 / 2009$ & Ms. Incompetent & No & Yes & Yes & Yes & No & No & Yes \\
\hline WLS30023 & $3 / 2 / 2009$ & Mr. Lazy & No & No & No & Yes & Yes & Yes & Yes \\
\hline WLS30022 & $2 / 27 / 2009$ & Ms. Incompetent & No & Yes & Yes & Yes & No & No & Yes \\
\hline WLS30021 & $2 / 26 / 2009$ & Ms. Malevolent & Yes & N/A & N/A & N/A & Yes & $\mathrm{N} / \mathrm{A}$ & Yes \\
\hline WLS30020 & $2 / 25 / 2009$ & Ms. Incompetent & No & Yes & Yes & Yes & No & No & Yes \\
\hline WLS30019 & $2 / 25 / 2009$ & Mr. Lazy & No & No & No & Yes & Yes & Yes & Yes \\
\hline WLS30018 & $2 / 24 / 2009$ & Ms. Malevolent & Yes & N/A & N/A & N/A & Yes & $\mathrm{N} / \mathrm{A}$ & Yes \\
\hline WLS30017 & $2 / 23 / 2009$ & Ms. Incompetent & No & Yes & Yes & Yes & No & No & Yes \\
\hline WLS30016 & $2 / 23 / 2009$ & Ms. Malevolent & Yes & N/A & N/A & N/A & Yes & N/A & Yes \\
\hline WLS30015 & $2 / 20 / 2009$ & Ms. Malevolent & Yes & $\mathrm{N} / \mathrm{A}$ & N/A & N/A & Yes & N/A & Yes \\
\hline WLS30014 & $2 / 19 / 2009$ & Mr. Lazy & No & No & No & Yes & Yes & Yes & Yes \\
\hline WLS30013 & $2 / 18 / 2009$ & Ms. Stellar & No & No & No & No & No & No & No \\
\hline WLS30012 & $2 / 17 / 2009$ & Ms. Stellar & No & No & No & No & No & No & No \\
\hline WLS30011 & $2 / 17 / 2009$ & Ms. Stellar & No & No & No & No & No & No & No \\
\hline WLS30010 & $2 / 13 / 2009$ & Ms. Stellar & No & No & No & No & No & No & No \\
\hline WLS30009 & $2 / 11 / 2009$ & Ms. Stellar & No & No & No & No & No & No & No \\
\hline WLS30008 & $2 / 10 / 2009$ & Ms. Stellar & No & No & No & No & No & No & No \\
\hline WLS30007 & $2 / 9 / 2009$ & Ms. Stellar & No & No & No & No & No & No & No \\
\hline WLS30006 & $2 / 9 / 2009$ & Ms. Stellar & No & No & No & No & No & No & No \\
\hline WLS30005 & $2 / 6 / 2009$ & Ms. Stellar & No & No & No & No & No & No & No \\
\hline WLS30004 & $2 / 5 / 2009$ & Ms. Stellar & No & No & No & No & No & No & No \\
\hline WLS30003 & $2 / 5 / 2009$ & Ms. Stellar & No & No & No & No & No & No & No \\
\hline WLS30002 & $2 / 3 / 2009$ & Ms. Stellar & No & No & No & No & No & No & No \\
\hline WLS30001 & $2 / 2 / 2009$ & Ms. Stellar & No & No & No & No & No & No & No \\
\hline
\end{tabular}

Figure 6: Non-compliance spillover/spillage study \#4, Tumult University, Wankowitz Labs.

In-sitsu/exposure: Exposure/restitution is the less dramatic and drastic measure. For example, simple exposure, or open acknowledgment of very minor indiscretions (e.g., not entirely following organization policies and procedures) and incorporation of means to prevent future indiscretions, might include an allocution or protocol deviation reported to the IRB with steps for prevention and a request for blanket waiver [30]. In terms of missing informed consent forms (ICFs), a resolution involving exposure and restoration might be conducting other informed consent sessions, obtaining substitute ICFs from study participants, and reporting a blanket protocol deviation and public allocution. This does not constitute restoring the situation to its original condition as if the infraction had not occurred. Rather, this is a form of corrective restoration and improvement redeeming the situation so that it is acceptable, workable, and livable.

Ex-sitsu/removal and replacement: On the other hand, removal/ replacement often involves digging up and abatement; for example, a drastic removal/replacement solution for missing ICFs might be simply locating and discarding the study participants' data for those missing an ICF and recruiting all new study participants, ensuring that the new participants document their informed consent. Such measures are far more drastic and thus can create more problems. For example, real troubles might start in cases where study participants' involvement in the research was contingent on their receiving the research results, only to discover that the results were jettisoned because protections for human research subjects were not observed. Inconceivably worse is a scenario in which there must be legally mandated monetary restitution or compensation (e.g., the nonconsensual injection of Guatemalans with syphilis study) [31]. The questions of what kind of action and how much action come down to whether the research would be worth saving and what is acceptable to the IRB. No one likes or wants to shoulder the costs of a cleanup or fix-up, but covering those costs should be incumbent on those culpable for the situation in the first place, which ultimately is the principal investigator.

Viability: What determines whether remediation is a viable option, as well as its actionable components, is an overall assessment of severity in terms of harmfulness, gravity or probability of recurrence, presence of willful misconduct, and extent and impact of problems balanced by the scientific importance of the loss of the research. Though the ideal would be "new" or the "way it was before" (i.e., 
perfect and pristine restoration), this is probably unrealistic. Put differently, the more realistic or reasonable goal is to get back as close to the standard(s) as possible and to when past practices were tolerable. This again is an IRB determination. The extent of comprehensiveness in any remediation is a compromise or balance between acceptable levels of repair carefully weighed against the costs and resources involved with implementation and the benefits gained.

\section{Prevention and Education-Preclusion and Deterrence}

Remediation components listed in most organization policies and procedures emphasize the prevention of future occurrences of problems with human research subjects protections, especially through enhanced education and training, but also through sanctions and punishment. These can be itemized from least to most restrictive/ punitive (Table 1).

\begin{tabular}{|l|l|}
\hline 1 & Additional education; \\
\hline 2 & Design changes in processes; \\
\hline 3 & Notification of Study Participants of issues/problems with the study; \\
\hline 4 & Enhanced external monitoring with direct review on areas of concern; \\
\hline 5 & Observation of processes by external observers; \\
\hline 6 & External intervention (i.e., "Preceptorship" or "Receivership") \\
\hline 7 & Suspension of study; \\
\hline 8 & Suspension of researcher privileges to conduct research; \\
\hline 9 & $\begin{array}{l}\text { Termination/Revocation of researcher privileges to conduct research; } \\
\text { and, }\end{array}$ \\
\hline 10 & Study termination. \\
\hline
\end{tabular}

Table 1: IRB sanctions and punishments for non-compliance

The particular IRB decides whether and how restrictions and punishments are dispensed ... or dispensed with altogether. However, continued patterns of wilful non-compliance that obviate basic regulatory requirements and principles of human research subjects protection are clearly unacceptable. They are grounds for sanctions up to and including study termination and revocation of researcher privileges to conduct research.

IRBs can dispense with restrictions and punishments taking into account that researchers have shown "good faith," to include allocution and (1) provision of a corrective remediation plan, (2) amelioration of defective processes, and (3) verification of the corrective actions and changes. Furthermore, the point of remediation is to not only correct past mistakes but also to learn from them. Therefore, given the fact that evidenced-based remediation education has shown favorable results in medicine [32-34], there have been the development of educational programs for inclusion in remediation efforts [35, 36].

\section{Near Zero Defects-Real Visible Change}

Going forward, near zero defects is the standard for evaluating the effects of remediation, bearing in mind that mistakes can still occur and realistically perfection is only an ideal. Real visible change is the window of comparison between pre- and post-remediation or baseline and after intervention. This also indicates a semblance of the preremediation condition and the adequacy of efforts to proof against further occurrence of problems as measured in predictive probabilities. Unlike other types of remediation (e.g., eco-remediation) that aim to reduce problems to acceptable levels, for human research subjects non-compliance, visible change should be $100 \%$. Thus, statistical comparisons are unnecessary because there should be no post-remediation variance with which to compare. If this is not the case, then it is evidence of ongoing and continuous non-compliance post-remediation and thus willful misconduct. Such continuing noncompliance would be legitimate justification for the IRB's termination of the research and even revocation of the researchers' privileges to conduct research and possible debarment from conducting research ever again.

\section{Discussion}

Undoubtedly, there is an inescapable professional obligation to ensure that research is conducted in an ethical and competent manner, which remediation cannot reduce, excuse, or exonerate. (Remediation cannot make it brand new or "like it never happened.") Nevertheless, remediation may be the only saving grace to redeem important, worthy research when errant problems and practices are uncovered with respect to human research subjects. Thus, to fill a gap in information in the human research subjects literature, this article has reported on remediation concepts and approaches that have practical implications. At the least, this exercise has broached a sensitive, controversial, shadowy, and taboo subject in terms of formulating remediation of non-compliance with human research subjects protections. At most, this report serves as a step toward providing practical opportunities that can redeem otherwise healthy and valuable research from indiscretions in human research subjects protection.

The information in this article is intended to provide ideas and methods that can be useful in tailoring reasonable and systematic human research subjects remediation efforts to particular circumstances. There is no attempt to provide a critical review or comparison and contrasting of different systems, as there are few, if any open-source reports of other systems with which to do so. Also, the ideas and methods reported herein are an amalgamation of what little is reported in terms of best practices on the subject. Once implemented, documented, evaluated, reported, and publicly acknowledged, better information about what works in terms of human research subjects remediation will be more readily available. Thus, human research subjects remediation itself will be progressively enhanced. Perhaps the hushed and embarrassed whispers around a forbidden subject will grow to the point of transformation into credible systematic study and scientific exposition. So, when errant human research subjects protection practices in redeemable research are uncovered, the study (ies) can be reformed and salvaged rather than abandoned, discarded, and buried. The end-state can be a refocusing on systemic problems that will more likely detect and prevent future problems [37]. Nevertheless, the paramount challenge in reducing regulatory problems, whatever their intent or character, is designing and instituting systems that can better alert, identify, inform on, and prevent problems before excessive correction and costs are necessary, and without excessive and needless blame and shame. Rather than expensive remediation programs, the focus should be on preventing the need for remediation in the first place [38-42]. 


\section{Limitations}

One prominent limitation for the systems described herein, especially visual displaying, is out sensibly they may appear to be unworkable for large and fragmented studies or on large samples. First, Figures 3-6 may have conveyed this misimpression because they were hypothetical ideal examples designed to concisely convey ideas or impressions and were limited in size the interest of brevity and saving space (ie., fit the page). It may be counterintuitive but visual displaying can actually enhance the global reach or overall picture of the problem(s). Second, anecdotally the systems and models, and approaches described herein have worked-well on at least 16 different and commonly related studies with off-site and remote operations where the studies had enrollments of anywhere between 120 and 15,000 human subjects and can at least easily track and portray patterns including up to several thousand or more deviations/ violations. For example, spreadsheets used as visual displays are but one yet effective technique. Another unique feature is that they can provide almost unlimited layered pages representing different studies that can be interconnected, if need be. They also practically have unlimited cells for individual subjects and unlimited columns that can easily include the 14 different primary research violations. Should their limit be exceeded, other spreadsheet files can be created as continuations and even interconnected. For this reason, the systems, models, and approaches reported herein have been presented conceptually and their translations into applications left to practitioners. Much like the spreadsheets their applications are only limited to the practitioners' imaginations.

\section{Acknowledgements}

This research was supported by a grant from the National Heart Lung Blood Institute P50HL083794 and the author gratefully acknowledges material support from the University of Texas-HSCHouston-Medical School Department of Internal Medicine Division of Medical Genetics.

\section{References}

1. DuBois JM, Anderson EE, Chibnall J (2013) Assessing the need for a research ethics remediation program. Clin Transl Sci 6: 209-213.

2. Chubin DE (1985) Research malpractice. Bioscience 35: 80-89.

3. Dingell JD (1993) Shattuck Lecture--misconduct in medical research. N Engl J Med 328: 1610-1615.

4. Burk DL (1993) Research misconduct: deviance, due process, and the disestablishment of science. George Mason Indiana Law Review 3: 305-515.

5. Grant D, Alfred KC (2007) Sanctions and recidivism: an evaluation of physician discipline by state medical boards. J Health Polit Policy Law 32: 867-885.

6. Dubois JM, Carroll K, Gibb T, Kraus E, Rubbelke T, et al. (2012) Environmental Factors Contributing to Wrongdoing in Medicine: A Criterion-Based Review of Studies and Cases. Ethics Behav 22: 163-188.

7. Marshall E (2000) Scientific misconduct. How prevalent is fraud? That's a million-dollar question. Science 290: 1662-1663.

8. Fanelli D (2009) How many scientists fabricate and falsify research? A systematic review and meta-analysis of survey data. PLoS One 4: e5738.

9. Bankert EA, Amdur RJ (2006) Institutional Review Board: Management \& function. Jones and Bartlett Publishers, Sudbury, MA; 85.

10. University of California (2009) Ethics and compliance plan: Report to the Compliance and Audit Committee of the Regents. July 14.

11. http://www.yale.edu/hrpp/
12. UC Berkely (2014) Perspect Clin Res

13. CDC (2010) "Human Research Protections" Policy. Science Administration, CDC-SA.

14. Groeger JS, Strosberg MA, Halpern NA, Raphaely RC, Kaye WE, et al. (1992) Descriptive analysis of critical care units in the United States. Crit Care Med 20: 846-863.

15. Angelos P, Murphy TF, Sampson H, Hollings DD, Kshettry V (2006) Informed consent, capitation, and conflicts of interest in clinical trials: views from the field. Surgery 140: 740-748.

16. Bramstedt KA, Kassimatis K (2004) A study of warning letters issued to Institutional Review Boards by the United States Food and Drug Administration. Clin Invest Med, 27: 316-323.

17. Black's Law Dictionary (2014) 10th standard edition (Bryan Garner, ed.). West Publishing Co., Inc.

18. de Vries R, Gordijn B (2009) Empirical ethics and its alleged meta-ethical fallacies. Bioethics 23: 193-201.

19. http://www.va.gov/ORO/Docs/Guidance/1058_01_RCRR_NCOMP_ Chart_12_01_2011.pdf

20. GAO (2000) VA RESEARCH: Protections for human subjects need to be strengthened. GAO/HEHS-00-155, Report to Congressional Requesters; USGPO: Washington, D.C, USA.

21. http://www.va.gov/ORO/Docs/Guidance/ 1058_01_RCRR_NCOMP_Chart_12_01_2011.pdf

22. Hilts PJ (1999) V.A. hospital is told to halt all research. N Y Times Web .

23. Steiner JE (2006) Clinical research law and compliance handbook. Jones and Bartlett Publishers, Sudbury MA, 199-205.

24. Efron R (1993) Scientific misconduct: undue process. Account Res 3: 223-238.

25. Dakins ME, Toll JE, Small MJ, Brand KP (1996) Risk-based environmental remediation: Bayesian Monte Carlo analysis and the expected value of sample information. Risk Anal 16: 67-79.

26. MacDonald JA, Small MJ (2006) Assessing sites contaminated with Unexploded Ordinance: Statistical modeling of ordinance spatial distribution. Environmental Science and Technology, 40, 931 - 938.

27. Ottesen RT, Alexander J, Langedal M, Haugland T, Hoygaard E (2008) Soil pollution in day-care centers and playgrounds in Norway: National action plan for mapping and remediation. Environ Geochem Health, 30: $623-637$

28. Beeler CK, Antes AL, Wang X, Caughron JJ, Thiel CE, et al. (2010) Strategies in Forecasting Outcomes in Ethical Decision-making: Identifying and Analyzing the Causes of the Problem. Ethics Behav 20: 110-127.

29. Mumford MD, Connelly S, Murphy ST, Devenport LD, Antes AL, et al. (2009) Field and Experience Influences on Ethical Decision-Making in the Sciences. Ethics Behav 19: 263-289.

30. Lee SK, Cowie SE (2001) MSJAMA: medical students and remediation of error. JAMA 286: 1082-1083.

31. Cohen IG, Adashi EY (2012) In the wake of Guatemala: the case for voluntary compensation and remediation. Am J Public Health 102: e4-6.

32. Antes AL, Wang X, Mumford MD, Brown RP, Connelly S, et al. (2010) Evaluating the effects that existing instruction on responsible conduct of research has on ethical decision making. Acad Med 85: 519-526.

33. Anderson MS, Horn AS, Risbey KR, Ronning EA, De Vries R, et al. (2007) What do mentoring and training in the responsible conduct of research have to do with scientists' misbehavior? Findings from a National Survey of NIH-funded scientists. Acad Med 82: 853-860.

34. Titus SL (2014) Evaluating U.S. medical schools' efforts to educate faculty researchers on research integrity and research misconduct policies and procedures. Account Res 21: 9-25.

35. https://ori.hhs.gov/blog/repair-program-provides-solution-redeemresearchers

36. DuBois J (2013) Opinion: remediating misconduct; should institutions invest in changing the behavior of scientists found guilty of violating research rules and ethics? The Scientist. May 14, 2013. 
Citation: Johnson J (2015) Remediation for Human Research Subjects Protections Non-Compliance: Concepts and Approaches. J Clinic Res Bioeth 6: 220. doi:.4172/2155-9627.1000220

Page 10 of 10

37. Mumford MD, Murphy ST, Connelly S, Hill JH, Antes AL, et al. (2007) Environmental influences on ethical decision making: climate and environmental predictors of research integrity. Ethics Behavior 17: 337-366.

38. Lakeman R, Fitzgerald M (2009) Ethical suicide research: a survey of researchers. Int J Ment Health Nurs 18: 10-17.

39. Boreland F, Lesjak M, Lyle D (2009) Evaluation of home lead remediation in an Australian mining community. Sci Total Environ 408: 202-208.
40. Burger J, Gochfeld M, Kosson DS, Powers CW, Friedlander B, et al. (2005) Science, policy, and stakeholders: developing a consensus science plan for Amchitka Island, Aleutians, Alaska. Environ Manage 35: 557-568.

41. Thomson JR, Moilanen AJ, Vesk PA, Bennett AF, Nally RM (2009) Where and when to revegetate: a quantitative method for scheduling landscape reconstruction. Ecol Appl 19: 817-828.

42. Elias RW, Gulson B (2003) Overview of lead remediation effectiveness. Sci Total Environ 303: 1-13. 